Supporting Information

\title{
Corrosion of Late- and Post-Transition Metals into Metal- Organic Chalcogenolates and Implications for Nanodevice Architectures
}

Matthew Yeung, ${ }^{1}$ Derek C. Popple, ${ }^{2}$ Elyse A. Schriber, ${ }^{3}$ Simon J. Teat, ${ }^{4}$ Christine M. Beavers, ${ }^{5}$ Aude Demessence, ${ }^{6}$ Tevye R. Kuykendall, ${ }^{7}$ J. Nathan Hohman ${ }^{3 *}$

${ }^{1}$ Department of Physics, Massachusetts Institute of Technology, Cambridge, MA, 02139, United States

${ }^{2}$ Department of Physics, University of California, Berkeley, Berkeley, 94720, California, United States

${ }^{3}$ Institute of Materials Science and Department of Chemistry, University of Connecticut, Storrs, Connecticut, 06268, United States

${ }^{4}$ Advanced Light Source, Lawrence Berkeley National Laboratory, Berkeley California 94720, United States

${ }^{5}$ Diamond Light Source, Harwell Science and Innovation Campus, Didcot, OX11 0DE, UK

${ }^{6}$ Univ Lyon, Université Claude Bernard Lyon 1, CNRS, Institut de recherches sur la catalyse et l'environnement de Lyon (IRCELYON), Villeurbanne 69626, France

${ }^{7}$ The Molecular Foundry, Lawrence Berkeley National Laboratory, Berkeley, California, 94720, United States

*corresponding author james.hohman@uconn.edu

Contents: Additional EDS, confocal PL, additional XPS data, and refinement detail for indium benzeneselenolate; additional X-ray diffraction spectra of the metals and corresponding MOCha, showing that the metals were consumed by the reaction (Figure S1); photoluminesence from the copper(I) benzeneselenolate product is observed using confocal microscopy (Figure S2); and a list of lattice parameters from the refinements performed (Table S1) (PDF). 

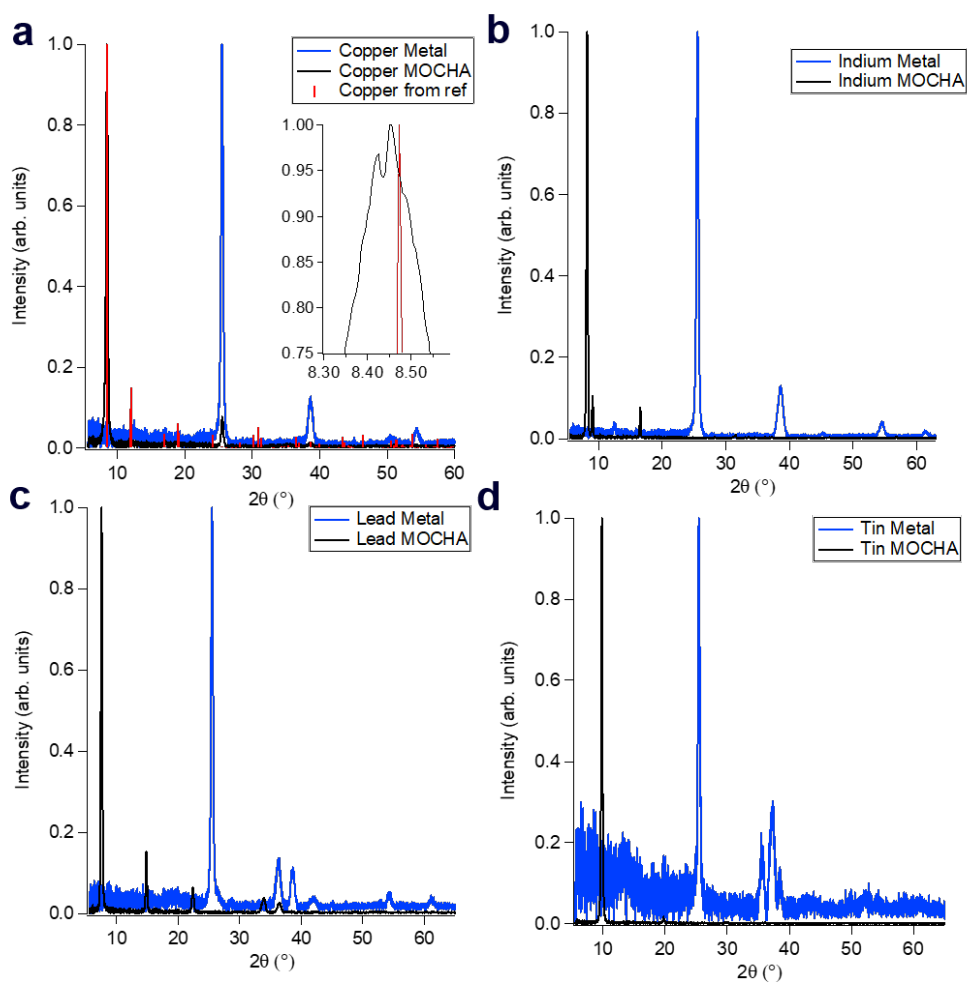

Figure S1. Additional X-ray diffraction spectra of the metals and corresponding MOCha showing that the metals were consumed by the reaction. a) The prominent low-angle peak from the experimental MOCha data aligns well with the reference ${ }^{1}$. a-d) The metal XRD showing conversion from metal to MOCha.

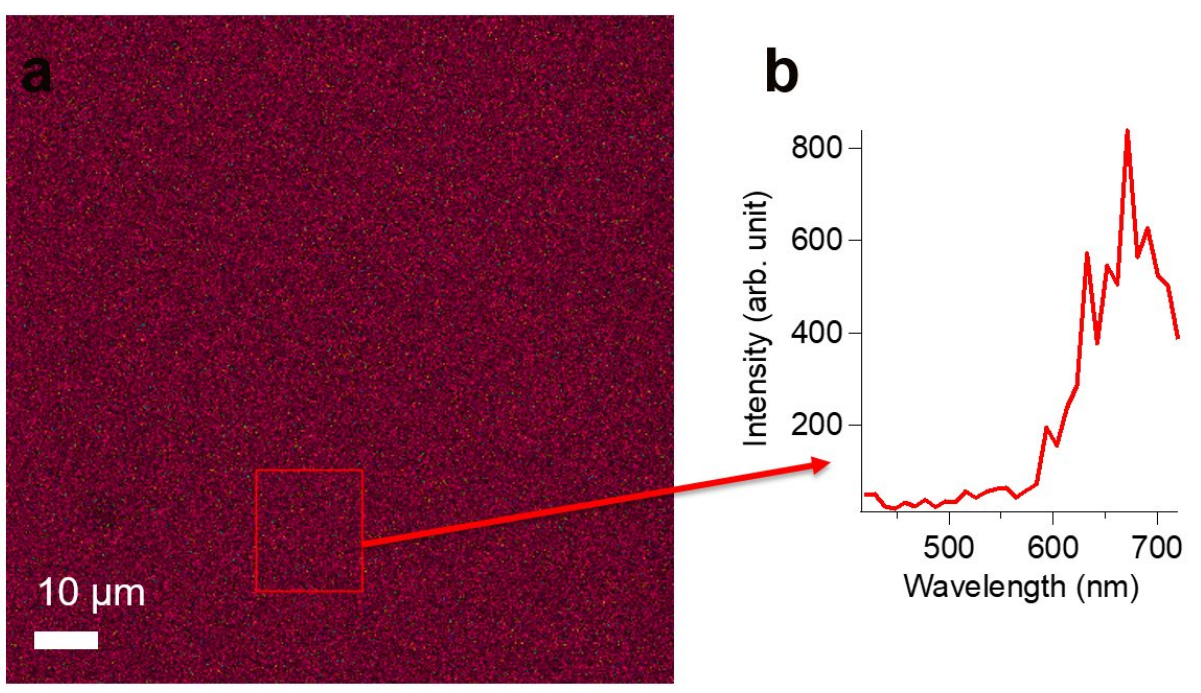

Figure S2. a) Photoluminesence from the copper (I) benzeneselenolate product is observed using confocal microscopy. b) The spectrum was collected using a bin size of $10 \mathrm{~nm}$. The spectral features are consistent with the results reported by Low et al. ${ }^{1}$ 

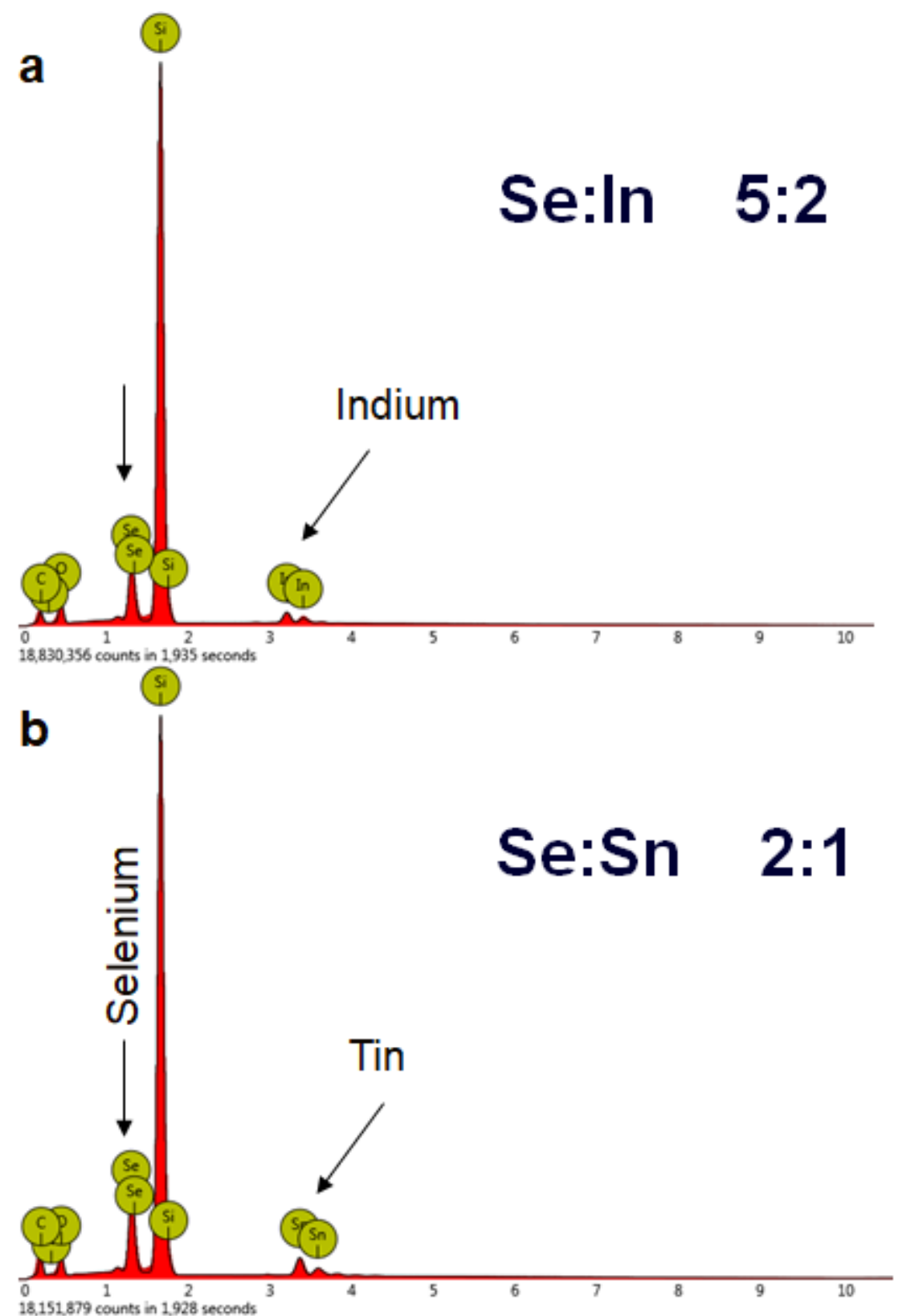

Figure S3. Energy dispersive spectroscopy data collected for the a) indium MOCha and b) tin MOCha and the corresponding elemental quantification table. The silicon and oxygen originate from the silicon dioxide substrate, which is quite thick in these samples. Approximate measured ratios for the elements of interest are given. 


\section{Additional XPS Discussion of the transformation of Metals into MOCha}

With the copper MOCha, the dominant feature is the $2 \mathrm{p}_{3 / 2}$ at $933 \mathrm{eV}$, and is consistent with $\mathrm{Cu}^{1+}$. This is in agreement with Low's reported structure for copper benzeneselenolate having copper in the +1 oxidation state. ${ }^{1}$ Additional peaks at $934 \mathrm{eV}$ with a satellite feature between 940 and $943 \mathrm{eV}$ are attributed to $\mathrm{Cu}^{2+}$. -4 The source of the copper (II) oxide can be attributed to both oxidation of the metal and to any decomposition of the MOCha. Before the growth, the metal already shows weak signals from the satellite peaks and the $\mathrm{O} 1 \mathrm{~s}$ (see Figure S4) also shows additional oxygen signal around the $\mathrm{SiO}_{2}$ peak, supporting the claim of copper (II) oxide.

The indium metal (see Figure S4) exhibited loss features associated with energy loss transitions a signature in indium metal, at $455 \mathrm{eV}$ and $464 \mathrm{eV} .^{5-7}$ These features disappear after the reaction, an indication that the indium is no longer found in the metallic state. Indium (III) oxide is also apparent, this is seen through the $3 \mathrm{~d}_{5 / 2}$ and $3 \mathrm{~d}_{3 / 2}$ peak broadening, in addition to the shoulder seen in the indium metal O1s data (see S4). After conversion, the In-MOCha exhibits some weak signals that appear to be due to residual indium metal and oxide. Residual metal is seen through the energy loss transition signature as seen in Figure S4.

The $\mathrm{Pb} 4 \mathrm{f}$ features at 138 and $143 \mathrm{eV}$ are largely unmodified after conversion, a result consistent with previous reports of the formation of lead sulfides and selenides. ${ }^{8-10}$ However, larger emerging shoulders at 136 and $142 \mathrm{eV}$ are observed, but could not be attributed to lead oxide, lead carbonate, or to the lead metal. It should be noted that the lead showed the lowest conversion ratio under the conditions examined, and unconverted metal is observed when performing SEM at higher working voltages. The peak width of the bare metal is slightly smaller than the peak width of the MOCha. The difference in full width at half maximum of the $4 \mathrm{f}_{7 / 2}$ and $4 \mathrm{f}_{5 / 2}$ peak is $130 \mathrm{meV}$ and $145 \mathrm{meV}$, respectively.

The tin metal exhibits two peaks for both the $3 \mathrm{~d}_{3 / 2}$ and $3 \mathrm{~d}_{5 / 2}$. The two $5 / 2$ peaks appear at $484.6 \mathrm{eV}$ and $486.3 \mathrm{eV}$ which is the metal and tin (II) oxide, respectively. ${ }^{11-12}$ The O1s also supports this as tin (II) has an apparent shoulder that is greater than the binding energy of the $\mathrm{SiO}_{2}$ peak. ${ }^{11,13-14}$ There are also some plasmon loss features observed to the higher binding energy side of the $3 \mathrm{~d}_{3 / 2}$ spin-orbit component, these

are attributed to tin metal and possibly the tin-selenide bond, as seen in previous studies on tin meta ${ }^{15}$ and tin sulfides. ${ }^{16}$ After conversion, the Sn (II) oxide peak greatly diminishes, resulting in one peak for the $3 \mathrm{~d}$ $5 / 2$ and $3 \mathrm{~d}_{3 / 2}$, instead of two. The $3 \mathrm{~d}_{5 / 2}$ peak is centered at $486 \mathrm{eV}$ while the $3 \mathrm{~d}_{3 / 2}$ peak is centered at $494 \mathrm{eV}$. 

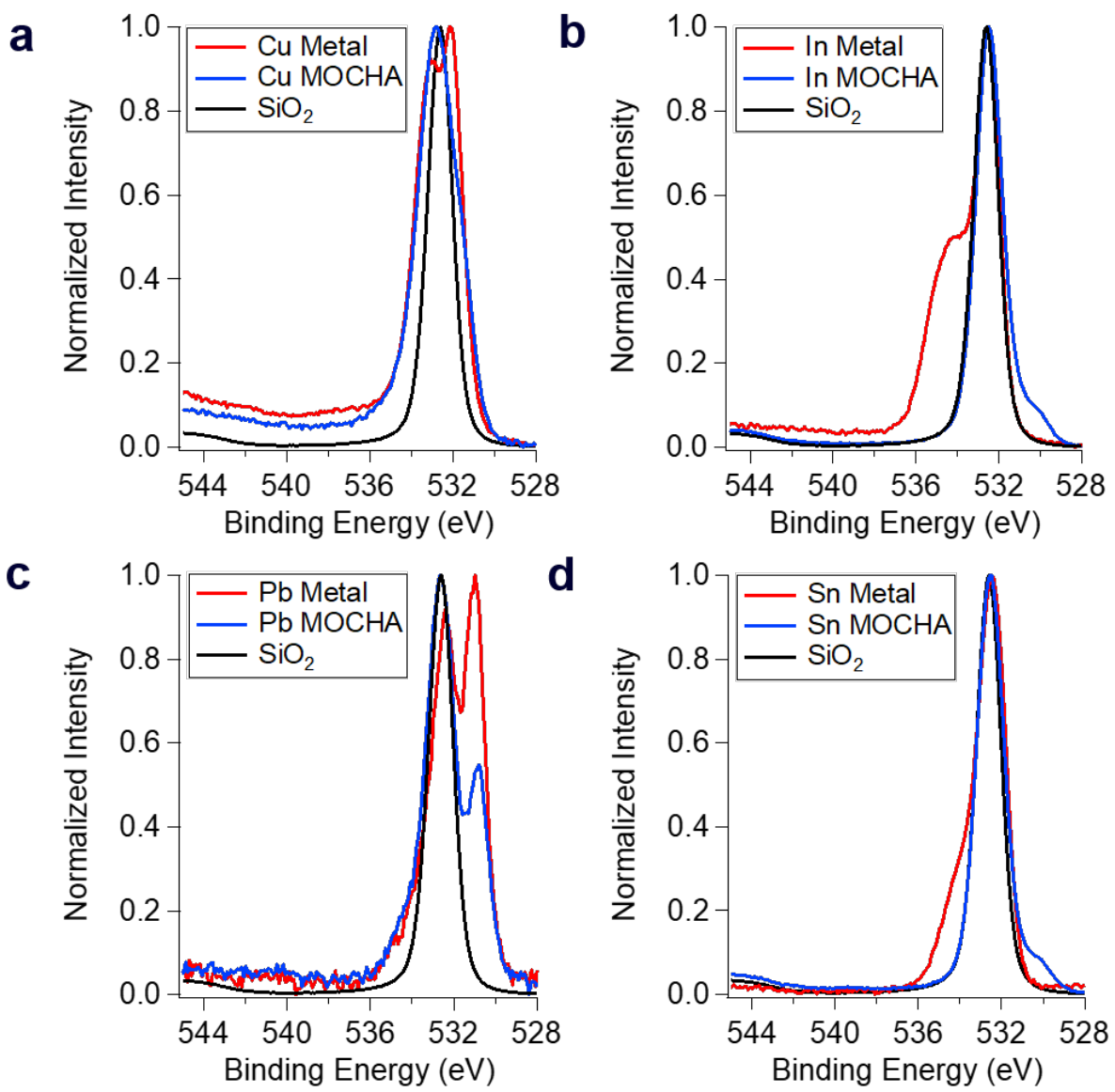

Figure S4. The O1s of the metal and corresponding MOCha with a silicon dioxide blank used as a reference are compared. The O1s signal is used as a proxy for metal oxides. a) The copper before and after growth are similar, but with some slight changes around the peak located around $533 \mathrm{eV}$. We interpret this result as an indication of the presence of copper oxide before and after the reaction, suggesting the growth did not fully convert the metal. b) The indium oxide in the metal is almost gone after growth, indicating near-complete conversion. c) The lead metal exhibits a considerable amount of oxide before and after the growth. As seen in the Pb4f signal, the metal exhibits more oxide, while in the $\mathrm{Pb}-\mathrm{MOCh}$, the signal is reduced. $\mathrm{d}$ ) The tin metal shows some oxidation and after the growth, the oxygen signal follows the silicon dioxide signal. 

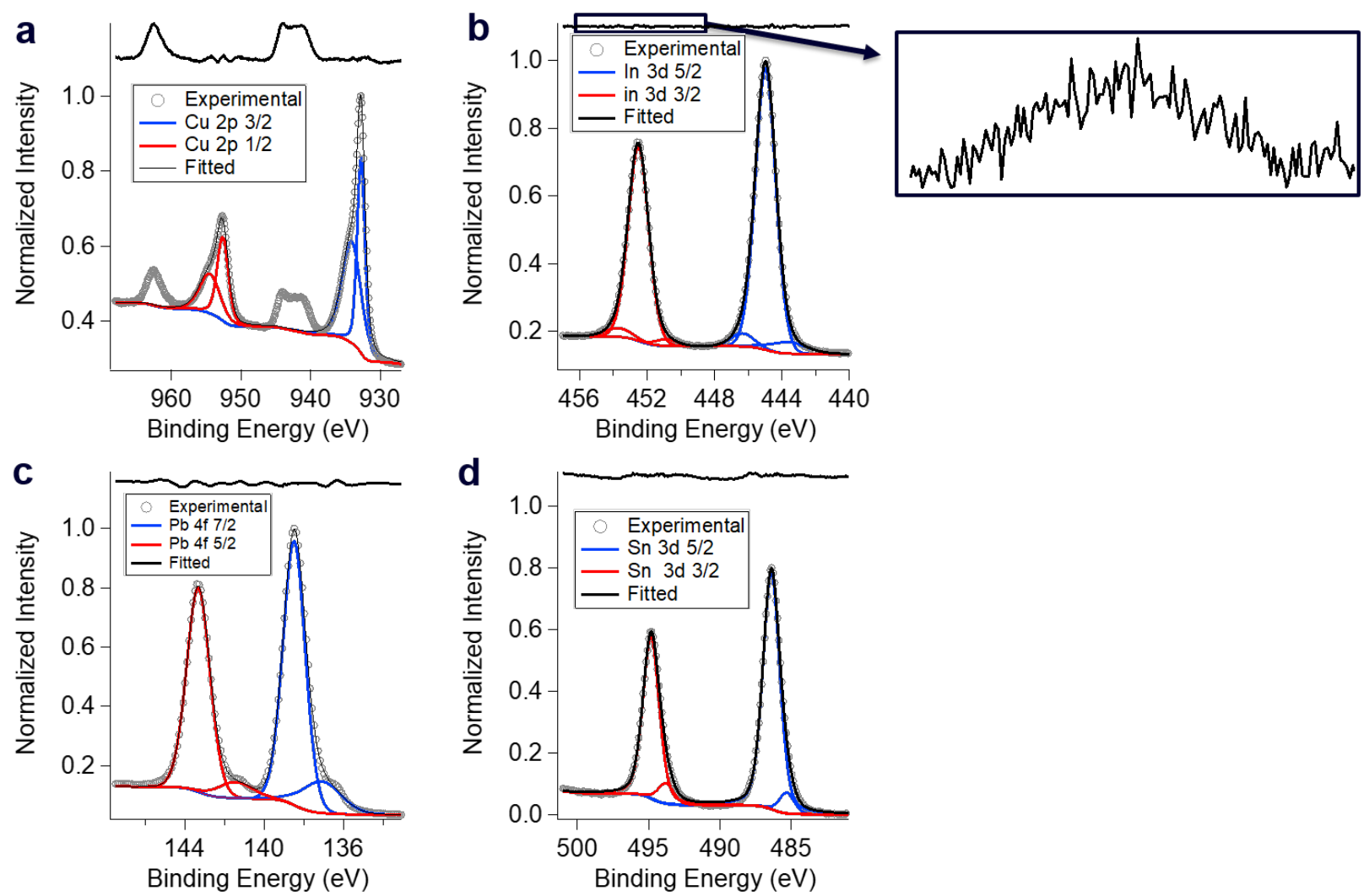

Figure S5. The fitted XPS of the four MOChas highlighting the products after the corrosion. a) The 2p $3 / 2$ peak located at $933 \mathrm{eV}$ being $\mathrm{Cu}$ (I) and the peak at $934 \mathrm{eV}$ is $\mathrm{Cu}$ (II). b) The indium $3 \mathrm{~d} 5 / 2$ peaks showing that there is one strong signal at $445 \mathrm{eV}$ with weak signals at $444 \mathrm{eV}$ and 446 , suggesting that there is trace oxide or metal. c) The lead $4 \mathrm{f} 7 / 2$ and $5 / 2$ peaks showing a large amount of a specific oxidation state and hints of oxide or other lead material. $d$ ) The tin $3 d 5 / 2$ peak showing that most of the surface contains a single oxidation state with trace oxide or impurities. 


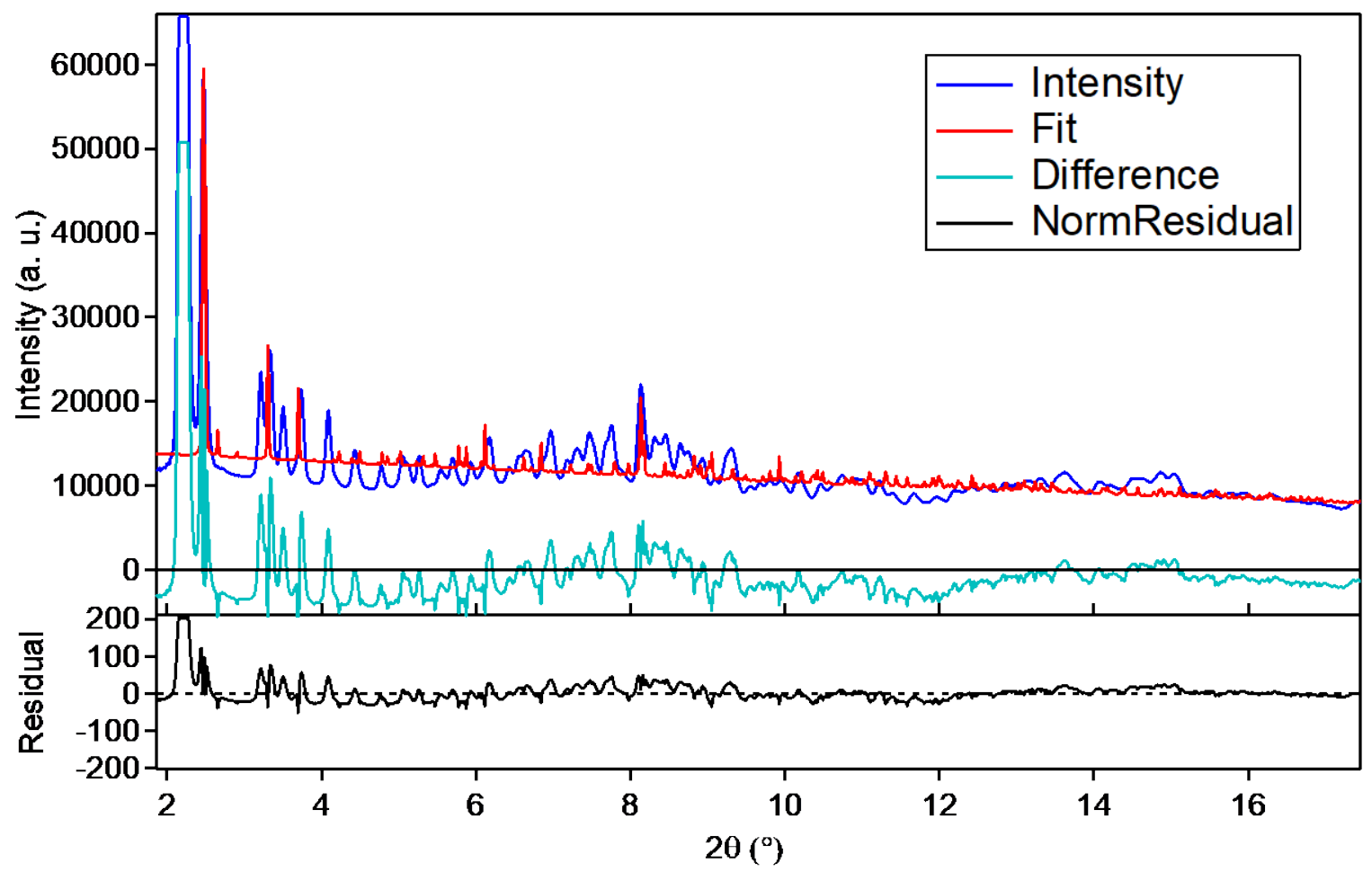

Figure S6 | The powder x-ray diffraction from Advanced Light Source (ALS) beamline 12.2.2 of the indium MOCha and corresponding refinement data.

After several samples of the indium (III) benzeneselenolate crystals were recovered from wafer surfaces and combined, it was loaded into the quartz capillary was placed onto the rotating stage and exposed to Xrays. The cerium oxide calibration standard used with the GSAS II software to establish penetration and wavelength values. ${ }^{18}$ The indium data were loaded and integrated using the $\mathrm{CeO}_{2}$ controls. The plot in $\mathrm{S} 6$ shows that the first peak was saturated due to a long exposure time. Regardless, refinements of the XRD spectra, unit cell, sample to detector distance, were attempted using 20 iterations. The purpose of the refinement is to show that some triclinic phase but no monoclinic phase is detected. The result is a fractional phase of 0.7779 for the triclinic compound with the following lattice parameters, $a=7.25341 \AA, b=$ $11.35891 \AA, c=22.96876 \AA, \alpha=81.272^{\circ}, \beta=85.466^{\circ}$, and $\gamma=83.956^{\circ}$. As seen from $\mathrm{S} 6$, numerous peaks cannot be attributed to the triclinic phase, monoclinic phase, or indium metal. Thus, the presence of additional peaks is attributed to additional product phases and meant the data could be refined no further. 


\begin{tabular}{|l|l|l|l|l|l|l|}
\hline Refinement conditions & $\mathrm{a}(\AA)$ & $\mathrm{b}(\AA)$ & $\mathrm{c}(\AA)$ & $\alpha\left(^{\circ}\right)$ & $\beta\left(^{\circ}\right)$ & $\gamma\left(^{\circ}\right)$ \\
\hline $\begin{array}{l}\text { 1. Triclinic and } \\
\text { Monoclinic In(SePh) } \\
\text { indium metal }\end{array}$ & 7.20517 & 11.12793 & 22.71202 & 82.812 & 86.127 & 83.824 \\
\hline 2. Triclinic In(SePh) $)_{3}$ only & 7.25341 & 11.35891 & 22.96876 & 81.272 & 85.466 & 83.956 \\
\hline $\begin{array}{l}\text { 3. Triclinic In(SePh) } \\
\text { first peak ignored }\end{array}$ & 7.24032 & 11.36422 & 22.95725 & 81.062 & 85.629 & 84.288 \\
\hline
\end{tabular}

Table 1. The list of lattice parameters from the refinements performed.

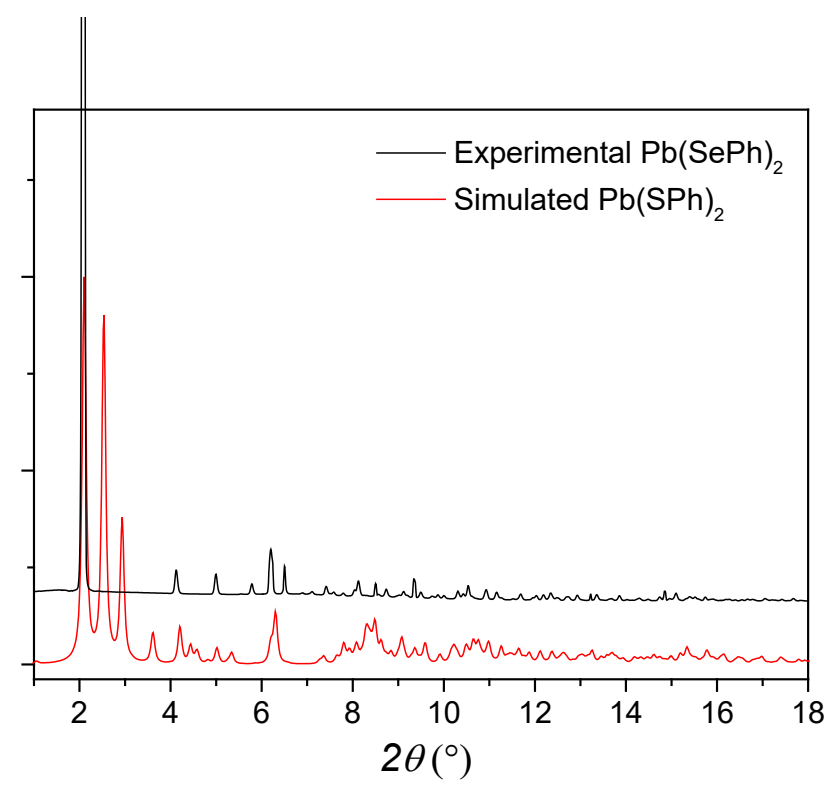

Figure S7. Experimental and simulated PXRD patterns of $\mathrm{Pb}(\mathrm{SePh})_{2}$ and $\mathrm{Pb}(\mathrm{SPh})_{2}$, respectively $(\lambda=$ $0.4959 \AA)$.

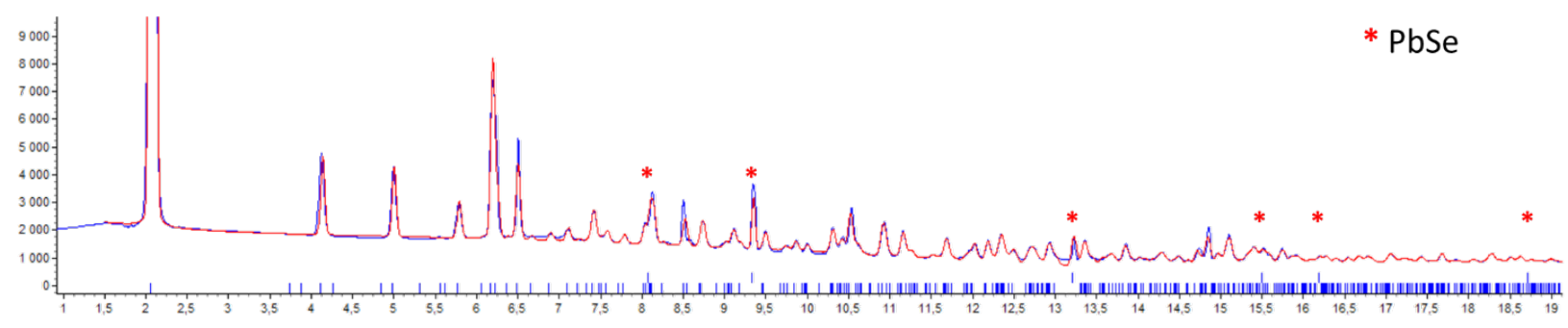

Figure $\mathrm{S} 8$. Experimental powder XRD pattern of $\mathrm{Pb}(\mathrm{SePh})_{2}$ (blue) and the corresponding pattern matching (red) in Pbcn space group with the unit cell parameters: $\mathrm{a}=27.6340 \AA, \mathrm{b}=5.8346 \AA, \mathrm{c}=15.1941 \AA$ and associated with the presence of $\mathrm{PbSe}$ as impurities.

The pattern matching was performed with the TOPAS software. ${ }^{19}$ It converged to a satisfactory profile factor $\left(R_{\mathrm{wp}}=7.86\right)$. 


\section{Additional References}

1. Low, K.-H.; Li, C.-H.; Roy, V. A. L.; Chui, S. S.-Y.; Chan, S. L.-F.; Che, C.-M., Homoleptic Copper(I) Phenylselenolate Polymer as a Single-Source Precursor for $\mathrm{Cu}_{2} \mathrm{Se}$ Nanocrystals. Structure, Photoluminescence and Application in Field-Effect Transistor. Chemical Science 2010, 1, 515-518.

2. Scrocco, M., Satellite Structure in the X-ray Photoelectron Spectra of $\mathrm{CuO} \mathrm{Cu}_{2} \mathrm{O}$. Chem. Phys. Lett. 1979, 63, 52-56.

3. Ivanauskas, R.; Janickis, V.; Jasulaitienè, V., Comparison characterization of copper selenide thin layers prepared on polyamide 6 films by sorption-diffusion method. Cent. Eur. J. Chem. 2013, 11, 636643.

4. Chen, X. Q.; Li, Z.; Dou, S. X., Ambient Facile Synthesis of Gram-Scale Copper Selenide Nanostructures from Commercial Copper and Selenium Powder. ACS Appl. Mater. Interfaces 2015, 7 , 13295-13302.

5. Donley, C.; Dunphy, D.; Paine, D.; Carter, C.; Nebesny, K.; Lee, P.; Alloway, D.; Armstrong, N. R., Characterization of Indium-Tin Oxide Interfaces Using X-ray Photoelectron Spectroscopy and Redox Processes of a Chemisorbed Probe Molecule: Effect of Surface Pretreatment Conditions. Langmuir 2002, $18,450-457$.

6. $\quad$ Lin, A. W. C.; Armstrong, N. R.; Kuwana, T., X-ray Photoelectron/Auger Electron Spectroscopic Studies of Tin and Indium Metal Foils and Oxides. Anal. Chem. 1977, 49, 1228-1235.

7. Reddy, I. N.; Ch Venkata, R.; Migyung, C.; Jaesool, S.; Dongseob, K., Structural, optical and XPS study of thermal evaporated In 2 O 3 thin films. Mater. Res. Express 2017, 4, 086406.

8. Sun, X.; Gao, K.; Pang, X.; Yang, H.; Volinsky, A. A., Study on the growth mechanism and optical properties of sputtered lead selenide thin films. Appl. Surf. Sci. 2015, 356, 978-985.

9. Zaiats, G.; Yanover, D.; Vaxenburg, R.; Tilchin, J.; Sashchiuk, A.; Lifshitz, E., PbSe-Based Colloidal Core/Shell Heterostructures for Optoelectronic Applications. Materials 2014, 7.

10. Ren, Y. X.; Dai, T. J.; Luo, W. B.; Liu, X. Z., Fabrication of Lead Selenide Thin Film Photodiode for Near-Infrared Detection via $\mathrm{O}_{2}$-Plasma Treatment. J. Alloys Compd. 2018, 753, 6-10.

11. Shuttleworth, D., Preparation of metal-polymer dispersions by plasma techniques. An ESCA investigation. J. Phys. Chem. 1980, 84, 1629-1634.

12. Zatsepin, D. A.; Zatsepin, A. F.; Boukhvalov, D. W.; Kurmaev, E. Z.; Gavrilov, N. V., Sn-loss effect in a Sn-implanted a-SiO2 host-matrix after thermal annealing: A combined XPS, PL, and DFT study. Appl. Surf. Sci. 2016, 367, 320-326.

13. Ansari, S. G.; Dar, M. A.; Dhage, M. S.; Kim, Y. S.; Ansari, Z. A.; Al-Hajry, A.; Shin, H.-S., A novel method for preparing stoichiometric $\mathrm{SnO}_{2}$ thin films at low temperature. Rev. Sci. Instrum. 2009, $80,045112$.

14. Kwoka, M.; Ottaviano, L.; Passacantando, M.; Santucci, S.; Czempik, G.; Szuber, J., XPS study of the surface chemistry of L-CVD $\mathrm{SnO}_{2}$ thin films after oxidation. Thin Solid Films 2005, 490, 36-42.

15. Fondell, M.; Gorgoi, M.; Boman, M.; Lindblad, A., An HAXPES study of Sn, SnS, SnO and $\mathrm{SnO}_{2}$. J. Electron Spectrosc. Relat. Phenom. 2014, 195, 195-199.

16. Cruz, M.; Morales, J.; Espinos, J. P.; Sanz, J., XRD, XPS and 119Sn NMR study of tin sulfides obtained by using chemical vapor transport methods. J. Solid State Chem. 2003, 175, 359-365.

17. Stan, V. C.; Beavers, M. C.; Kunz, M.; Tamura, N. Quantum Beam Science 2018, 2

18. Toby, B. H.; \& Von Dreele; R. B. GSAS-II: the genesis of a modern open-source all purpose crystallography software package. Journal of Applied Crystallography 2013, 46(2), 544-549.

19. Topas V4.2: General Profile and Structure Analysis Software for Powder Diffraction Data, Bruker AXS Ltd, 2008. 